
and Caroline S. Hill (10 December 2013)

Science Signaling 6 (305), ra106. [DOI: 10.1126/scisignal.2004416]

The following resources related to this article are available online at http://stke.sciencemag.org.

This information is current as of 13 December 2013.

Article Tools Visit the online version of this article to access the personalization and article tools: http://stke.sciencemag.org/cgi/content/full/sigtrans;6/305/ra106

\section{Supplemental Materials}

Related Content

\section{References}

Glossary

Permissions
"Supplementary Materials" http://stke.sciencemag.org/cgi/content/full/sigtrans;6/305/ra106/DC1

The editors suggest related resources on Science's sites:

http://stke.sciencemag.org/cgi/content/abstract/sigtrans;5/233/ec189

http://stke.sciencemag.org/cgi/content/abstract/sigtrans; $1 / 46 /$ eg8

http://stke.sciencemag.org/cgi/content/abstract/sigtrans;1/36/pe41

This article cites 37 articles, 20 of which can be accessed for free:

http://stke.sciencemag.org/cgi/content/full/sigtrans;6/305/ra106\#otherarticles

Look up definitions for abbreviations and terms found in this article:

http://stke.sciencemag.org/glossary/

Obtain information about reproducing this article:

http://www.sciencemag.org/about/permissions.dtl 


\title{
Controlling Long-Term Signaling: Receptor Dynamics Determine Attenuation and Refractory Behavior of the TGF- $\beta$ Pathway
}

\author{
Pedro Vizán, ${ }^{1 \star}$ Daniel S. J. Miller, ${ }^{1}$ Ilaria Gori, ${ }^{1}$ Debipriya Das, ${ }^{1}$ \\ Bernhard Schmierer, ${ }^{2 \dagger \ddagger}$ Caroline S. Hill ${ }^{1 \ddagger}$
}

\begin{abstract}
Understanding the complex dynamics of growth factor signaling requires both mechanistic and kinetic information. Although signaling dynamics have been studied for pathways downstream of receptor tyrosine kinases and $G$ protein (heterotrimeric guanine nucleotide-binding protein)-coupled receptors, they have not been investigated for the transforming growth factor- $\beta$ (TGF- $\beta$ ) superfamily pathways. Using an integrative experimental and mathematical modeling approach, we dissected the dynamic behavior of the TGF- $\beta$ to Smad pathway, which is mediated by type I and type II receptor serine/threonine kinases, in response to acute, chronic, and repeated ligand stimulations. TGF- $\beta$ exposure produced a transient response that attenuated over time, resulting in desensitized cells that were refractory to further acute stimulation. This loss of signaling competence depended on ligand binding, but not on receptor activity, and was restored only after the ligand had been depleted. Furthermore, TGF- $\beta$ binding triggered the rapid depletion of signaling-competent receptors from the cell surface, with the type I and type II receptors exhibiting different degradation and trafficking kinetics. A computational model of TGF- $\beta$ signal transduction from the membrane to the nucleus that incorporates our experimental findings predicts that autocrine signaling, such as that associated with tumorigenesis, severely compromises the TGF- $\beta$ response, which we confirmed experimentally. Thus, we have shown that the long-term signaling behavior of the TGF- $\beta$ pathway is determined by receptor dynamics, does not require TGF- $\beta$-induced gene expression, and influences context-dependent responses in vivo.
\end{abstract}

\section{INTRODUCTION}

Cells respond continually to their environment by inducing appropriate programs of gene expression, which in turn modulate cell behavior. In many cases, this is achieved by the binding of extracellular ligands to receptors on the surface of responding cells, triggering activation of signal transduction pathways that regulate expression of target genes. For many ligands, the molecular components of such signaling pathways are well understood, but prediction of how rapidly a cell will respond to a ligand, how strong or sustained the response will be, or how cells adapt to chronic or repeated ligand stimulations requires understanding of the dynamics of the system. Elucidating these complex modes of signaling is crucial for determining how these pathways function in physiological and pathological contexts in vivo, but for many signal transduction pathways, our knowledge of the dynamics of signaling is limited.

Transforming growth factor- $\beta$ (TGF- $\beta$ ) belongs to a superfamily of secreted cytokines that signal through the activation of serine/threonine kinase receptors on the cell surface (1). These ligands are crucial for early embryonic development and tissue homeostasis, and TGF- $\beta$ signaling is deregulated in several human diseases, including cancer and fibrosis (2).

${ }^{1}$ Developmental Signalling Laboratory, Cancer Research UK London Research

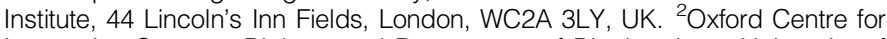
Integrative Systems Biology and Department of Biochemistry, University of Oxford, South Parks Road, Oxford OX1 3QU, UK

*Present address: Center for Genomic Regulation, E-08003 Barcelona, Spain. tPresent address: Department of Biosciences and Nutrition, Karolinska Institutet, SE-141 83 Stockholm, Sweden

‡Corresponding author. E-mail: caroline.hill@cancer.org.uk (C.S.H.); bernhard. schmierer@ki.se (B.S.)
Signaling requires two types of receptors: type I and type II, which interact upon ligand binding. The type II receptor phosphorylates and activates the type I receptor, which then propagates the signal. The best-studied intracellular substrates of the TGF- $\beta$ type I receptor kinase ALK5 are the receptor-regulated Smads, Smad2 and Smad3, which are phosphorylated at their extreme $\mathrm{C}$ termini. When phosphorylated, these Smads form homomeric complexes or heteromeric complexes with Smad4 and accumulate in the nucleus, where they regulate the transcription of many different genes and, as a result, control a wide range of cellular functions (3). The pathway is not linear but, rather, a dynamic network in which the Smads constantly shuttle between the cytoplasm and the nucleus (4). In stimulated cells, this shuttling provides a mechanism by which cells monitor receptor activity. Moreover, continuous receptor trafficking also occurs between the plasma membrane and the cytosol, and both receptors as well as ligand are internalized upon stimulation (5-7).

In contrast to the rapid kinetics of signaling by tyrosine kinase receptors, the kinetics of Smad phosphorylation are slow (8), with Smad2 phosphorylation peaking about 1 hour after ligand exposure, then declining over the next 8 hours (9). Several mechanisms have been proposed to explain this signal attenuation (10). A prominent one involves negative feedback, in which receptor degradation is mediated by complexes of Smad7 with either of the E3 ubiquitin ligases Smurf1 or Smurf2, all of which are synthesized in response to TGF- $\beta(11,12)$. Receptor dephosphorylation mediated by a GADD34-PP1c complex recruited by Smad7 has additionally been demonstrated (13). Phosphorylated Smad2 (PSmad2) degradation, promoted by secondary phosphorylation of Smad2 in the nucleus (14), and ligand depletion (15) have also been reported to play roles in signal termination. Several of these mechanisms, in particular 
those requiring Smad7, are thought to require the action of TGF- $\beta$ target genes in a negative feedback loop. However, the TGF- $\beta$ pathway fully attenuates even in the presence of protein synthesis inhibitors, such as cycloheximide $(9,16)$, indicating that the mechanism governing attenuation relies on proteins constitutively present in the cells before they receive the signal. Moreover, how cells respond to a subsequent ligand exposure during the attenuated state is currently not known.

Here, we have applied an integrative experimental and computational modeling approach to understand the dynamics of TGF- $\beta$ signaling and to dissect the mechanisms determining signal attenuation and cellular responsiveness to repeated ligand stimulations. We have shown that TGF- $\beta$ stimulation induces a refractory period in which cells are unresponsive to further acute ligand stimulation. This desensitization occurred independently of target gene expression and accounted for the signal attenuation observed after acute ligand stimulation. We have shown that rapid depletion of signaling-competent receptors in response to TGF- $\beta$ binding and their slow replenishment produces the refractory state and attenuated signaling. We have built an ordinary differential equation-based model that simulates the observed behaviors associated with long-term TGF- $\beta$ signaling. The model predicts that high autocrine signaling, which occurs, for instance, in certain late-stage tumors (17), would reduce cell responsiveness to an acute TGF- $\beta$ stimulus. We have confirmed this prediction experimentally with cancer cell lines.

\section{RESULTS}

\section{A refractory state triggered by acute TGF- $\beta$ signaling}

TGF- $\beta$ signal intensity can be monitored by measuring abundance of PSmad2. When human keratinocytes (HaCaT cells) are exposed to TGF- $\beta$, PSmad2 peaks at about 1 hour after stimulation, then gradually declines over the next 6 to 8 hours (Fig. 1A) $(9,14)$. We investigated whether this signal attenuation was due to ligand depletion or degradation, as previously reported (15), or to cell insensitivity to ligand. Medium taken from cells treated with a saturating concentration of TGF- $\beta(2 \mathrm{ng} / \mathrm{ml})$ for 8 hours induced phosphorylation of Smad2 in naïve cells (Fig. 1B, compare lanes $\mathrm{b}$ and $\mathrm{d}$ ), indicating that, under these conditions, ligand depletion had not occurred to a sufficient extent to explain the attenuated signaling. However, cells previously stimulated with TGF- $\beta$ for 8 hours failed to induce Smad2 phosphorylation when exposed to fresh ligand (Fig. 1B, compare lanes $\mathrm{b}$ and $\mathrm{e})$, demonstrating that the cells were in a refractory state. The signal attenuation after initial ligand exposure and the refractory state were not dependent on changes in the amounts of total Smad2 or ALK5, which remained stable throughout the experiment (Fig. 1B). Moreover, it was not unique to $\mathrm{HaCaT}$ cells, but was observed in other human and mouse cell lines (fig. S1).

We next investigated whether 1 hour of signaling triggered the refractory state. Because the abundance of PSmad2 was maximal at this time point, we treated the cells with the ALK5 catalytic inhibitor SB-431542 for 1 hour after the initial TGF- $\beta$ stimulation to substantially reduce PSmad2 levels (4) before washing out the inhibitor and incubating with fresh TGF- $\beta$. Cells treated with SB-431542 alone and then washed were competent to respond to TGF- $\beta$, demonstrating that the inhibitor washout was efficient (Fig. 1C, compare lanes a and b). Pretreatment of cells with TGF- $\beta$ for 1 hour before addition of SB-431542, however, almost completely prevented PSmad 2 induction in response to fresh TGF- $\beta$ after the inhibitor washout, indicating that the refractory state was triggered after only 1 hour of TGF- $\beta$ stimulation (Fig. $1 C$, lanes $c$ and $d$ ). The fact that a short exposure to ligand was sufficient to provoke a refractory state suggested that new protein synthesis in response to TGF- $\beta$ was unlikely to
A
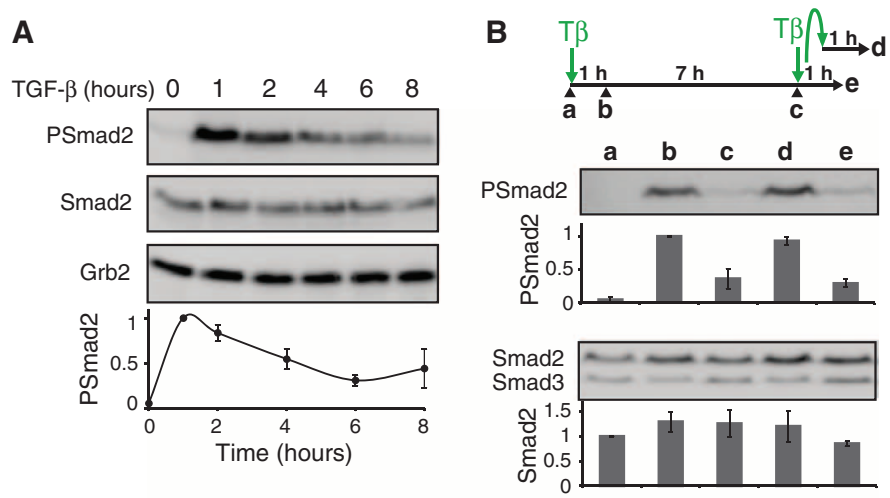

C
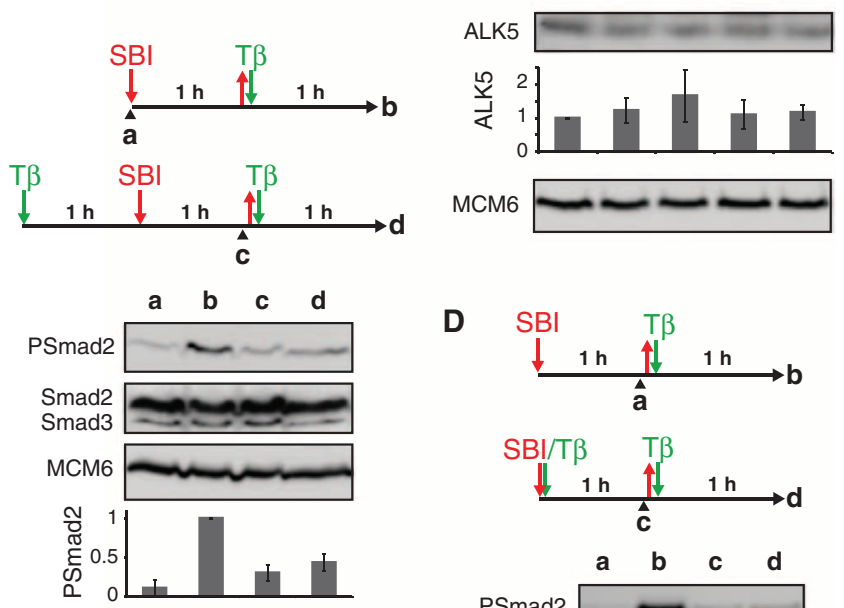

D
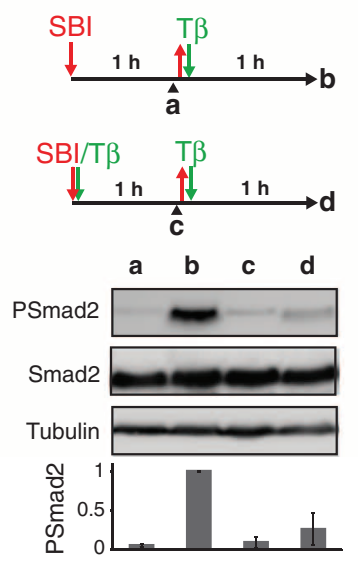

Fig. 1. TGF- $\beta$ stimulation triggers a refractory state. (A) HaCaT cells were treated with TGF- $\beta$ for the times indicated. (B) $\mathrm{HaCaT}$ cells were treated for 1 hour with TGF- $\beta$ (T $\beta$ ) (b) or for 8 hours (c), followed by reinduction with fresh TGF- $\beta$ for 1 hour (e). TGF- $\beta$-containing medium that had been in contact with cells for 8 hours was used to induce naïve cells for 1 hour (d). (C) Cells were treated with TGF- $\beta$ for 1 hour followed by 1 hour of SB-431542 (SBI) to reduce the amount of PSmad2 (c). Cells were then washed and reinduced with fresh TGF- $\beta$ for 1 hour (d). A control experiment without the initial TGF- $\beta$ treatment is also shown (b). (D) SB-431542 was added, or not, simultaneously with TGF- $\beta$ to HaCaT cells for 1 hour, before washing and reinduction with TGF- $\beta$ for 1 hour. In all cases, immunoblots of whole-cell lysates were probed with antibodies against the indicated proteins. Grb2, MCM6, and tubulin are loading controls. In the experimental schemes, green arrows indicate addition of TGF- $\beta$; curved arrow, induction of naïve cells with conditioned medium; red arrows, addition or removal of SB-431542. A representative blot is shown for each panel. Quantifications are shown below the blots and are the normalized (relative to loading control) average and SDs of three independent replicates in (A), (C), and (D), and the normalized averages (relative to loading control) and ranges of two independent experiments in (B). In (A) and (B), the amount of PSmad2 after a 1-hour TGF- $\beta$ stimulation was set to 1 , and in (C) and (D), the amount of PSmad2 after a 1-hour TGF- $\beta$ stimulation after SB-431542 washout was set to 1. 
play a role. Therefore, we investigated whether binding of the ligand to receptors was sufficient for attenuation and induction of the refractory state or whether the kinase activity of the ligand-bound TGF- $\beta$ receptors was also necessary. Cells were incubated with SB-431542 with or without TGF- $\beta$ for 1 hour, then washed and restimulated with TGF- $\beta$ for 1 hour. Treatment with ligand, even in the absence of active receptors, was sufficient to render the cells almost insensitive to a second exposure to TGF- $\beta$ (Fig. 1D, compare lanes a and b with lanes $\mathrm{c}$ and $\mathrm{d}$ ).

These findings revealed that signal attenuation is not due to ligand depletion, but rather to loss of cellular responsiveness, which occurs independently of negative feedback through induction of TGF- $\beta$ target genes. Thus, the cells adapt to the presence of TGF- $\beta$.

\section{Kinetic characterization of the refractory state}

Continuous trafficking of TGF- $\beta$ receptors between endosomal compartments and the plasma membrane has been reported $(5,6,18)$. By analogy with the Smads, which shuttle between the cytosol and nucleus to monitor receptor activity, trafficking of receptors between endosomes and the plasma membrane may continuously monitor the presence of extracellular ligand (19). However, the observed refractory behavior suggests that all available competent receptors are rapidly occupied within 1 hour of exposure to ligand, whereupon cells appear unable to signal beyond the limits imposed by trafficking of competent receptors to the plasma membrane.

To investigate this further, we asked how long cells required exposure to TGF- $\beta$ to reach maximal production of PSmad2, measured at 1 hour. To remove TGF- $\beta$ at specific times, we used an antibody against TGF- $\beta$ that prevents receptor binding (ligand-neutralizing antibody) and an isotype-matched immunoglobulin G1 (IgG1) monoclonal antibody as a control (20). When added simultaneously with TGF- $\beta$, the neutralizing antibody, but not the control antibody, abolished signaling (Fig. 2A, lanes $\mathrm{c}$ and $\mathrm{d}$ ). We then added the neutralizing antibody at different times after TGF- $\beta$ stimulation (Fig. 2A) and observed that similar amounts of PSmad 2 were produced at 1 hour when the control or ligand-neutralizing antibody was added 5 or $10 \mathrm{~min}$ after TGF- $\beta$. Thus, only $5 \mathrm{~min}$ of ligand exposure was sufficient to trigger most of the PSmad2 response detected at 1 hour.

We reasoned that the amount of ligand might also affect the refractory behavior observed, so we investigated how the pathway responded to different doses of TGF- $\beta$. The concentration of TGF- $\beta$ used throughout this study was $2 \mathrm{ng} / \mathrm{ml}$, which is a saturating concentration. By contrast, $0.1 \mathrm{ng} / \mathrm{ml}$ is a limiting concentration that produces a submaximal PSmad2 response (fig. S2). We tested the cellular response to a second saturating concentration of TGF- $\beta$ after exposure to different concentrations of TGF- $\beta$ $(2,0.5$, or $0.1 \mathrm{ng} / \mathrm{ml})$. After an initial induction with TGF- $\beta$ (2 or $0.5 \mathrm{ng} / \mathrm{ml})$, the cells were refractory to a further stimulation (Fig. 2B). However, after stimulation with $0.1 \mathrm{ng} / \mathrm{ml}$ TGF- $\beta$, cells showed a small induction of PSmad2 upon restimulation, suggesting that full receptor occupancy is important for the refractory behavior (Fig. 2B).

To investigate how long cells required to fully recover their responsiveness once ligand had been removed, we exposed HaCaT cells to TGF- $\beta$, and once the signal had naturally attenuated, we added neutralizing antibody to mimic TGF- $\beta$ removal. Four hours of antibody treatment reduced the amount of PSmad 2 to basal, indicating that even in the attenuated state, the cells responded to the TGF- $\beta$ in the medium. Thus, although the cells cannot produce a maximal response to a second TGF- $\beta$ exposure, they detect depletion of TGF- $\beta$ from the medium (Fig. $2 \mathrm{C}$, compare lanes $\mathrm{c}$ and $\mathrm{d}$ ). The neutralizing antibody was washed out at different times over a period of 24 hours (see fig. S3A for confirmation of washout efficiency), and the cells were restimulated with TGF- $\beta$ for 1 hour (Fig. $2 \mathrm{C}$ ). Cellular responsiveness to TGF- $\beta$ increased from 4 to 24 hours, with the amount of PSmad2 at 12 and 24 hours similar to that in cells not exposed to antibody.

From the previous experiment, we concluded that cells require 12 to 24 hours after ligand removal to completely recover their capacity to respond to TGF- $\beta$. However, the neutralizing antibody was used to artificially remove TGF- $\beta$. We reasoned that in vivo cells would not start to recover responsiveness until they had depleted the ligand themselves, for instance, by cellular uptake. To determine how long HaCaT cells need to deplete TGF- $\beta$ from the medium, we measured TGF- $\beta$ in the medium at different times after stimulation by enzyme-linked immunosorbent assay (ELISA) and found that by 30 hours, ligand was substantially depleted (fig. S3B). This was corroborated by the observation that the medium that had been in contact with $\mathrm{HaCaT}$ cells for 30 hours failed to stimulate naïve cells (fig. S3C). We therefore compared the behavior of cells chronically exposed to ligand (addition of TGF- $\beta$ every 10 hours for 30 hours) with those induced once and left for 30 hours (Fig. 2D). Cells exposed once to TGF- $\beta$ partially responded to a second TGF- $\beta$ stimulation 30 hours later (Fig. 2D, compare lanes $\mathrm{c}$ and d), indicating that they had consumed the ligand and begun to recover competent receptors. In contrast, cells induced every 10 hours exhibited an attenuated PSmad 2 response that was not further increased by exposure to TGF- $\beta$ for 1 hour (Fig. 2D, lanes e and $\mathrm{f}$ ).

\section{Mechanisms underlying the refractory state}

Signal attenuation after an acute stimulus has been attributed to negative feedback through TGF- $\beta$ target genes, such as those encoding Smad7, Smurf1, and Smurf2, which promote inactivation or degradation of receptors, or both (10). Phosphorylated Smads have also been proposed to be primed for degradation (14). However, we found that in the presence of cycloheximide, which blocks new protein synthesis, the attenuation of the TGF- $\beta$ signal as monitored by the quantity of PSmad 2 still occurred, and Smad 2 abundance remained constant (Fig. 3A). By contrast, the proteasomal inhibitor MG-132 abolished attenuation and the amount of PSmad2 remained stable (Fig. 3A). This stabilization of PSmad2 was not observed when receptor activity was inhibited with SB-431542 (Fig. 3B), suggesting that PSmad2 was not directly degraded, but rather turnover of the receptor was affected by MG-132. When both MG-132 and cycloheximide were used simultaneously, we observed that phosphorylation of Smad2 was not maintained to the same extent as that observed with MG-132 alone, indicating that new protein synthesis contributes to the signal during the attenuation phase (Fig. 3A).

Because protein degradation was required for the attenuation of the signal and the signal itself must induce a negative feedback to explain the attenuation, we hypothesized that TGF- $\beta$ stimulation might increase the rate of receptor degradation. Using antibodies specific for the type I receptor ALK5 (21) and the type II receptor TßRII (fig. S4), we monitored the abundance of endogenous receptors after different treatments. During signal attenuation, the total amount of each receptor remained unchanged (Figs. 1B and 3A). However, when protein synthesis was inhibited, the receptors were rapidly degraded, and this was prevented by the addition of MG-132 (Fig. 3A). We used the degradation rates in the presence of cycloheximide to measure half-lives of the receptors. However, we could not detect a significant difference in the half-life of either of the receptors in the presence or absence of TGF- $\beta$, when total receptor pools were analyzed (Fig. 3C). The half-lives found were $\sim 2$ hours for T $\beta$ RII and $\sim 4$ hours for ALK5 (Fig. 3, A and C), which are short compared with the half-life of Smad2 (Fig. 3, A and C). These findings, however, do not exclude the possibility of an increased rate of degradation of a small subfraction of receptors, for example, those binding TGF- $\beta$, which has been observed for T $\beta$ RII in other cell lines $(22,23)$. 
A

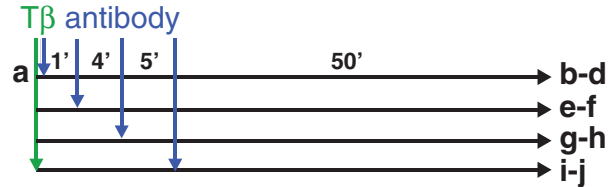

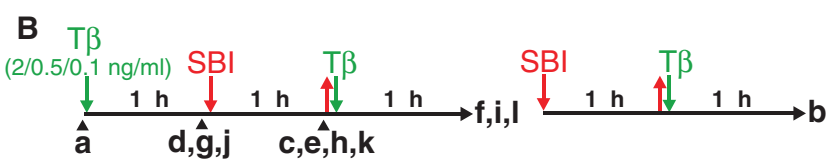

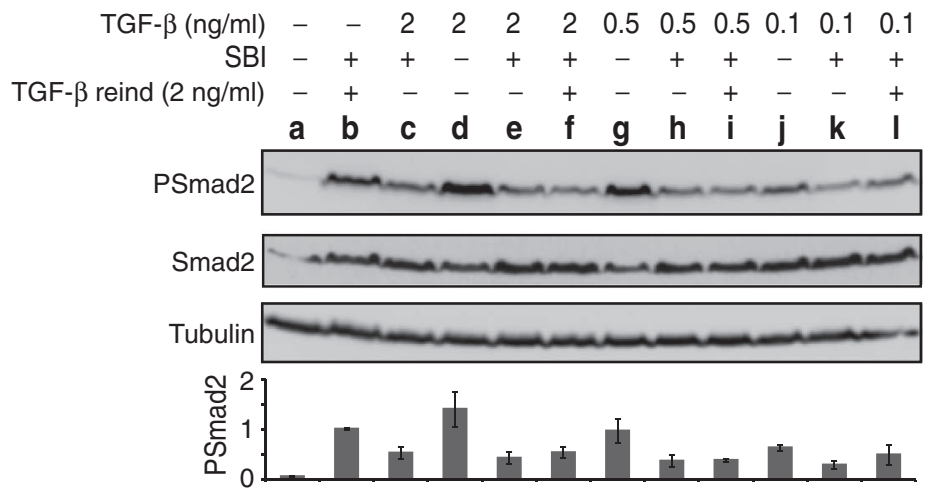

C

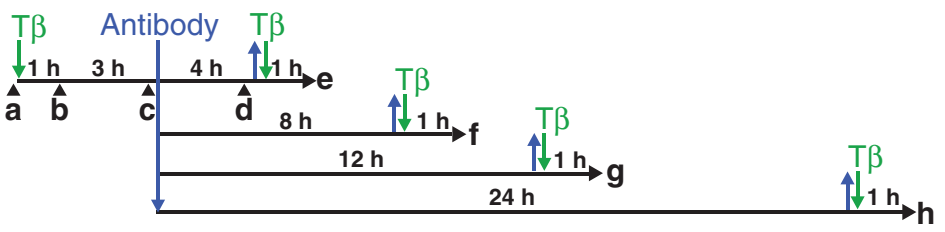

D
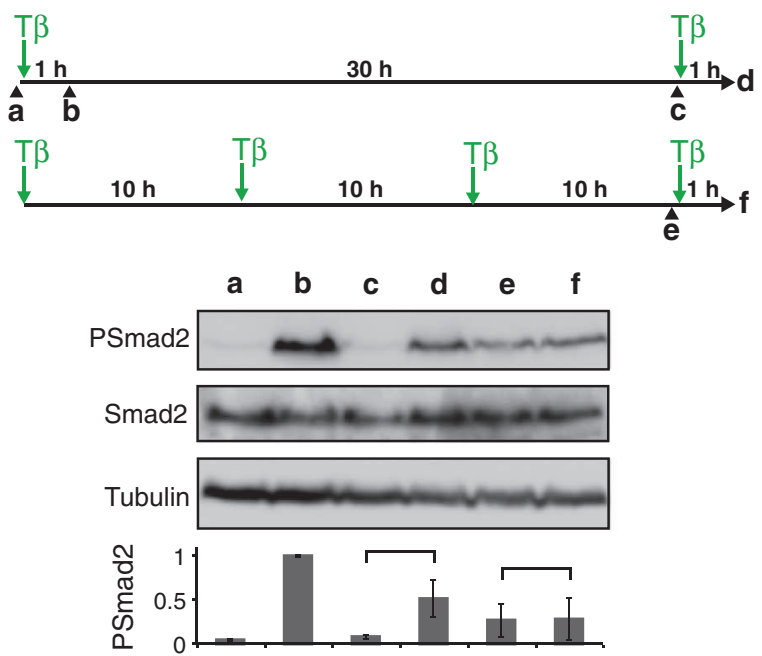

Fig. 2. Characterization of the refractory behavior. (A) HaCaT cells were treated with TGF- $\beta$ (T $\beta$ ) for 1 , 5, or 10 min before addition of a TGF- $\beta$ neutralizing antibody, or a control antibody for 59,55 , or 50 min, respectively, as indicated. Inductions of PSmad2 are also shown for cells induced with TGF- $\beta$ for 1 hour and for cells treated simultaneously with TGF- $\beta$ and the antibodies for 1 hour. (B) HaCaT cells were treated with the indicated concentrations of TGF- $\beta$ for 1 hour, the signal was inhibited with SB-431542 for 1 hour, and after washout, cells were reinduced with TGF- $\beta$ ( $2 \mathrm{ng} / \mathrm{ml})$. PSmad2 was assayed by Western blot. (C) Cells were induced with TGF- $\beta$ for 4 hours, and then neutralizing antibody was added. At different times, the antibody was washed out and TGF- $\beta$ was added for 1 hour. (D) Acute or chronic signaling was mimicked by stimulating HaCaT cells with TGF- $\beta$ once or every 10 hours, respectively. After 30 hours, cells were reinduced for 1 hour. In all cases, PSmad2 and total Smad2 were assayed by Western blot using tubulin or MCM6 as a loading control. The experimental schemes are as in Fig. 1, except that addition of antibody is shown as a blue arrow. A representative blot is shown for each panel. Quantifications are the normalized (relative to loading control) average and ranges of two independent experiments for (A), (B), and (D) and the average and SDs of three independent replicates for $(C)$. In (A), the amount of PSmad2 at every time point in the presence of control antibody was set to 1 , and additional normalization against control antibody at the different time points was performed to enable comparison at different times of TGF- $\beta$-neutralizing antibody addition. In (B), the amount of PSmad2 after a 1-hour TGF- $\beta$ stimulation after SB-431542 washout was set to 1. In (C) and (D), the amount of PSmad2 after a 1 -hour TGF- $\beta$ stimulation was set to 1 . 
Fig. 3. Mechanism of the refractory behavior. (A to C) $\mathrm{HaCaT}$ cells were treated with TGF- $\beta$ for the times indicated with or without cycloheximide and MG-132, separately and in combination. In (B), SB-431542 was added 1 hour after the initial addition of the TGF- $\beta$ and MG-132 treatment. In all cases, whole-cell extracts were analyzed by Western blot using the antibodies indicated.

(D) Left panels: $\mathrm{HaCaT}$ cells were treated with TGF- $\beta$ for the times indicated, and then surface proteins were biotinylated at $4^{\circ} \mathrm{C}$. Cells were then lysed, and biotinylated proteins were pulled down and Westernblotted with the antibodies indicated. As controls, unstimulated cells were also treated identically, but without biotin (-Biotin), or were surface-biotinylated and subsequently reduced to remove the biotin group (Reduced) Right panels: Wholecell lysates from the untreated cells and those stimulated with TGF- $\beta$ for 10 min, 1 hour, 8 hours, and 48 hours were assayed by Western blotting for PSmad2, ALK5, and T $\beta R I I$, with MCM6 as a loading control. In all cases, a representative blot is shown for each panel. Quantifications are shown below the blots and are the normalized (relative to loading control) average and ranges of two independent experiments in (A) and (B), the normalized (relative to loading control) average and SDs of three independent replicates in (C), and the average and range of two independent experiments in (D).

To determine whether changes in the amount of receptor at the cell surface could account for the refractory behavior of the cells, and if so, which of the TGF- $\beta$ receptors was responsible, we studied the dynamics of

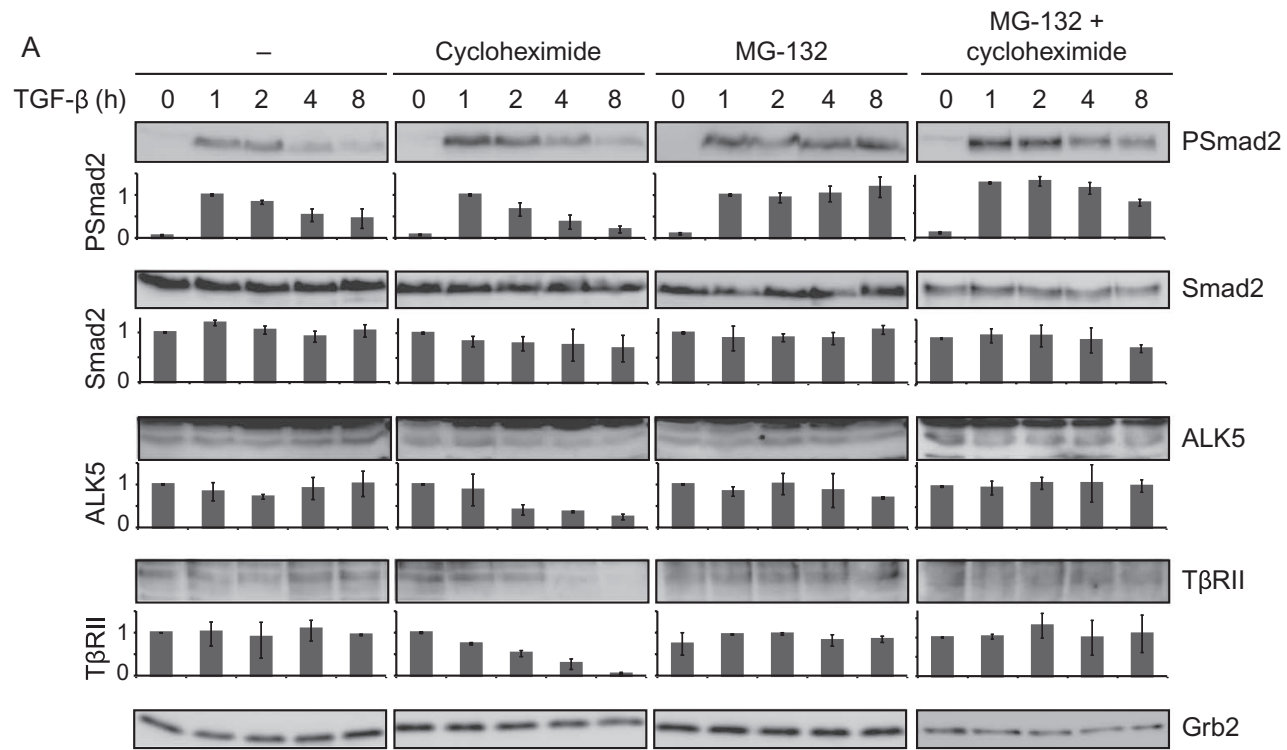

\begin{tabular}{llllll} 
B & \multicolumn{3}{c}{ SB-431542 } \\
TGF- $\beta$ (h) & 0 & 1 & $\downarrow$ & \\
& $\downarrow$ & 4 &
\end{tabular} MG-132 + + + + +

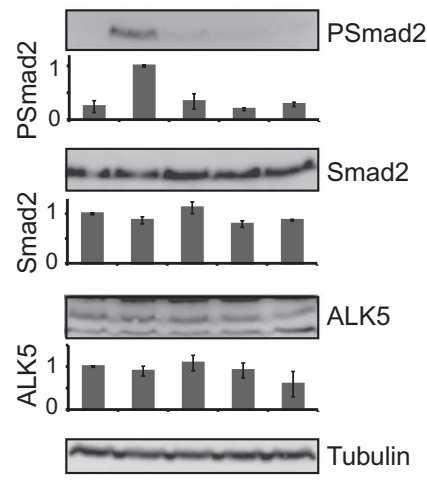

D

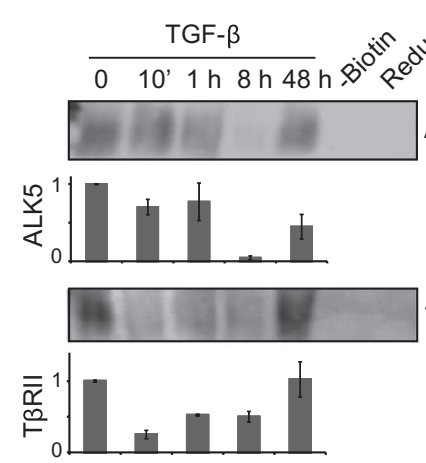

C
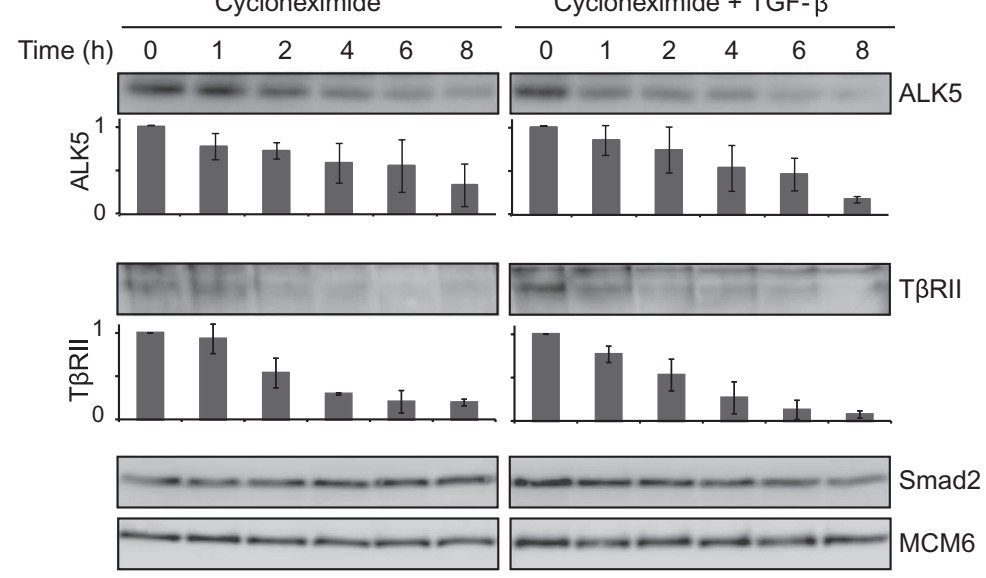

Surface receptors

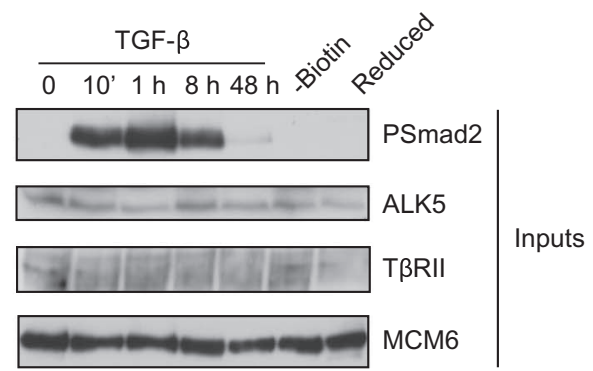

surface receptors in response to different times of TGF- $\beta$ stimulation. We have shown above that maximal TGF- $\beta$ receptor occupancy occurred within 5 to 10 min of TGF- $\beta$ stimulation (Fig. 2C) and cells are refractory 
to further acute responses after 1 or 8 hours of stimulation (Fig. 1). By 48 hours after TGF- $\beta$ induction, the cells had consumed all the TGF- $\beta$ in the medium and were fully responsive to acute stimulation (figs. S3 and S5). Using a surface biotinylation assay to measure the amount of endogenous surface receptors after different times of ligand stimulation, we showed that both the type I and type II receptors were efficiently depleted from the plasma membrane upon TGF- $\beta$ stimulation, although with different kinetics, and both had recovered by the 48 -hour time point (Fig. 3D and fig. S6, A and B). Similar results for receptor depletion were also observed in another cell line, MDA-MB-231 (fig. S6C), which shows the same refractory behavior (fig. S1). The dynamics of T $\beta$ RII trafficking appeared to be rate-limiting for the establishment of the refractory state, because T $\beta$ RII was substantially depleted from the cell surface after only 10 min of TGF- $\beta$ stimulation, whereas ALK5 was only maximally depleted by the 4-hour time point (Fig. 3D and fig. S6A). either taken from the literature or obtained by fitting the model to previous data (4).

\section{Reproducing the experimental data with the mathematical model}

The resulting model not only fitted the original kinetic data of nuclear accumulation of Smad2 (fig. S7) but also reproduced the attenuation behavior of the pathway after an acute treatment with TGF- $\beta$ (compare Fig. 4B with Fig. 1A, and see fig. S8). In the simulations, cells also exhibited insensitivity to restimulation at 8 hours (Fig. 4C) and at 1 hour after the initial stimulus (Fig. 4D), as demonstrated in the experiments (Fig. 1, B and $\mathrm{C}$, and fig. S8). The model reproduced the fast triggering of the refractory period, the dose response, and the long recovery time of between 12 and 24 hours shown experimentally (compare Fig. 5, A to C, with Fig. 2, A to C, and see fig. S8). It also captured the kinetics of cell-dependent

\section{Establishing a mathematical model to simulate TGF- $\beta$ signal attenuation and refractory behavior}

The data presented above suggest that rapid receptor internalization and slow recovery of the receptor at the surface, in conjunction with increased receptor degradation upon TGF- $\beta$ stimulation, might explain both signal attenuation after acute stimulation and the refractory behavior. To integrate all the kinetic data presented into a coherent dynamic framework and to test the feasibility of this proposal, we developed a mathematical model of TGF- $\beta$ signaling from the membrane into the nucleus. As a starting point, we used our previously published model of Smad dynamics (4). We replaced the rudimentary description of receptor biology contained in our previous model with a more realistic receptor module (Fig. 4A), which we derived from the data shown in Figs. 1 to 3 and from testing several plausible network structures. By fitting the resulting models to our data sets, we arrived at the network presented in Fig. 4A. This receptor module was the most successful in reproducing the data and required only a few assumptions, which are both biologically sound and supported by experimental evidence (see text S1, "Model conception: the receptor module").

We merged the new receptor module with the Smad shuttling network (4) (Fig. $4 \mathrm{~A}$ and tables $\mathrm{S} 1$ to $\mathrm{S} 3$ ). The Smad module and its parameter values were as described (4), except for those parameters that required optimization to allow consistent merging of both modules (see text S2, "Model parameterization"). Most independent parameters for the receptor module (table S1) were derived from the kinetic data presented in Figs. 1 to 3. The remaining independent parameters in the receptor module were
A

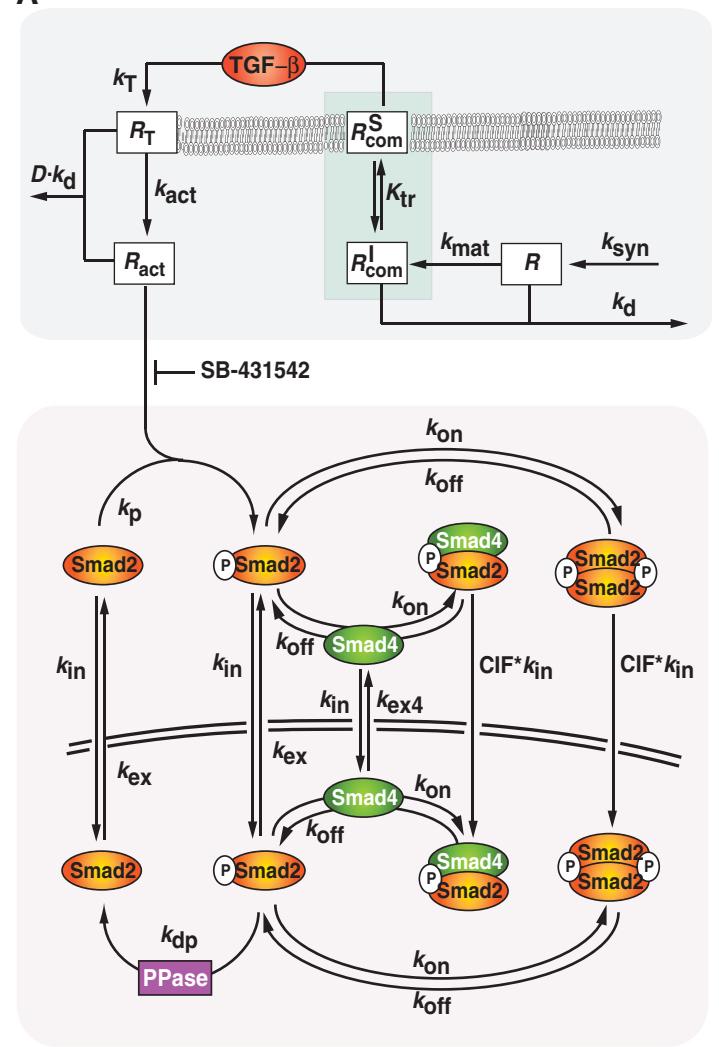

B (Fig. 1A)

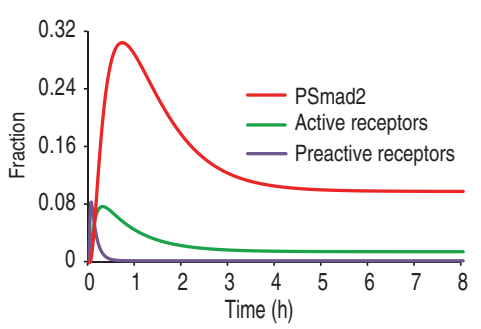

C

(Fig. 1B)
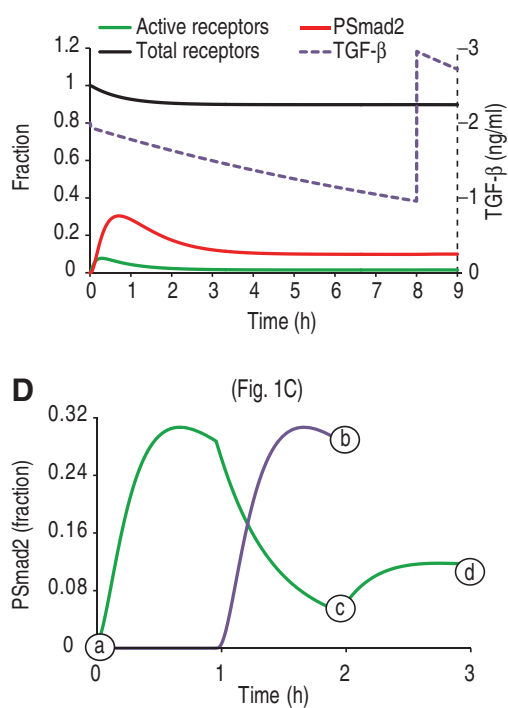

Fig. 4. The mathematical model captures both attenuation and refractory behavior. (A) Topologies of the receptor and Smad networks used for modeling. TGF- $\beta$ binds competent receptors at the surface $\left(R_{\text {com }}^{\mathrm{S}}\right)$, which become preactive $\left(R_{\mathrm{T}}\right)$ until they are internalized $\left(R_{\mathrm{act}}\right)$ and can phosphorylate Smad2. Not all receptors are able to signal; they need to mature $\left(k_{\text {mat }}\right)$ intracellularly $\left(R_{\mathrm{com}}^{\perp}\right) . R_{\mathrm{com}}^{\mathrm{S}}$ and $R_{\mathrm{com}}^{\perp}$ are assumed to be in equilibrium. Receptors are subject to synthesis $\left(k_{\text {syn }}\right)$ and degradation $\left(k_{d}\right)$ rates, with a factor $(D)$ to increase degradation of ligand-bound receptors. The Smad network is as previously described (4). (B to D) Model simulations (see also fig. S8). All model species are given as fractions of total Smad2 (or of total receptors in the absence of signaling), which are both set to 1. (B) TGF- $\beta$ time course (see Fig. 1A for PSmad2 and Fig. 3D for the receptor behavior). (C) Refractory behavior at 8 hours after TGF- $\beta$ stimulation (see Fig. 1B). (D) Refractory behavior after 1 hour of TGF- $\beta$. Letters correspond to experimental conditions shown in Fig. 1C; the colors represent the two different experimental schemes in Fig. 1C. 
ligand depletion (compare Fig. 5D with Fig. 2D and fig. S3B, and see fig. S8). Simulations of PSmad2 kinetics under different conditions, in particular in the presence of cycloheximide (reduced protein synthesis rate), MG-132 (reduced protein degradation rate), and SB-431542 (reduced Smad2 phosphorylation rate), showed a good agreement with the experimental observations (compare Fig. 5E with Fig. 3, A and B, and see fig. S9). A satisfactory model fit required that TGF- $\beta$-bound receptors had an increased degradation rate relative to unbound receptors (parameter $D>1$ ). Because only a small proportion of receptors are ligand-bound, ligand-enhanced degradation is predicted to only marginally affect the total pool of receptors (Fig. 5F) and would, thus, be likely undetectable in immunoblots (Fig. 3C and fig. S9).

Having established that the model could encapsulate long-term TGF- $\beta$ signaling dynamics consistent with the data, we used it to focus on the kinetics of the receptors. The simulations agreed well with the experimental data showing the rapid disappearance of surface receptors and their slow replenishment upon ligand removal (compare Fig. 5, G and H, with Fig. 3D; see also Fig. $5 \mathrm{C})$. In summary, the comprehensive model qualitatively explained the attenuation and the refractory behavior of TGF- $\beta$ signaling and is consistent with previously published quantitative data (4).

\section{Using the model to predict key regulated steps}

Model simulations can suggest which parameters influence signaling kinetics and are thus potential targets of regulatory mechanisms. The simulations identified the rate of receptor turnover as an important kinetic determinant. In the case of a long receptor half-life, the signal is sustained; an intermediate half-life gives rise to the observed attenuation behavior, and a very short halflife weakens the response and makes it even more transient (Fig. 6A). In addition, the receptor turnover rate directly determines how quickly TGF- $\beta$ is consumed and how rapidly surface receptors are depleted in response to a signal (Fig. 6A). A similar picture emerges if the ligand-induced receptor degradation-to-constitutive receptor degradation ratio (parameter $D$ ) is varied (Fig. $6 \mathrm{~B})$. If $D$ equals 1 , the response is strong and sustained, but it gets progressively weaker and more transient if $D$ increases, consistent with a previous model (24). In contrast, the initial concentration of surface
A

(Fig. 2A)

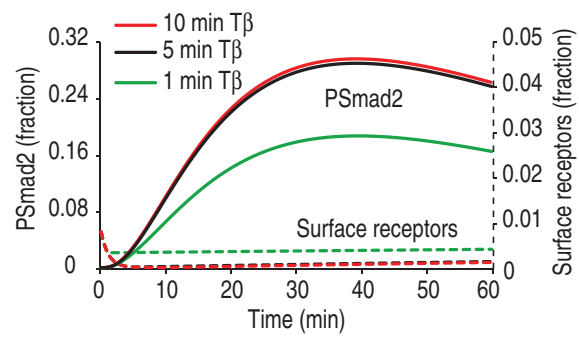

C

(Fig. 2C)

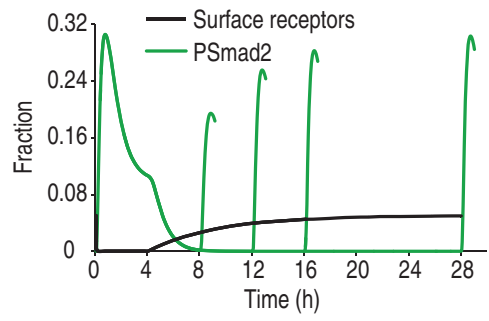

E

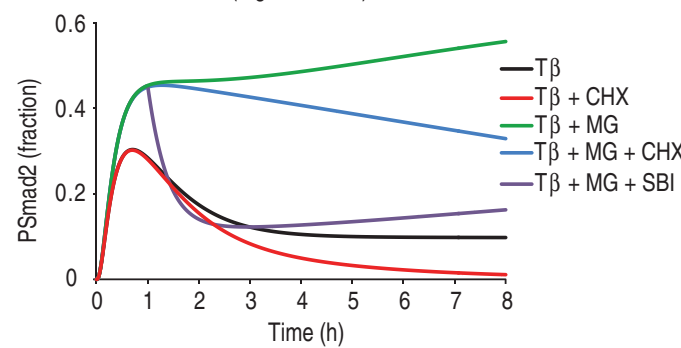

G

(Fig. 3D)

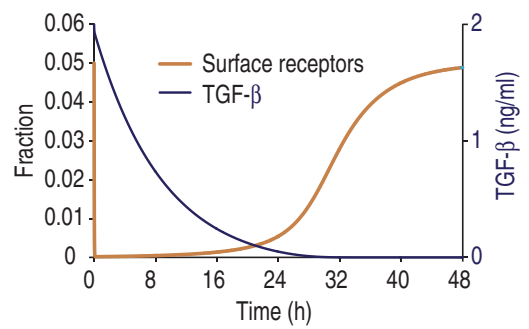

B

(Fig. 2B)

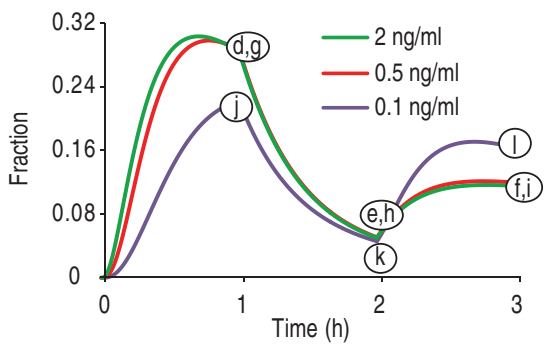

D

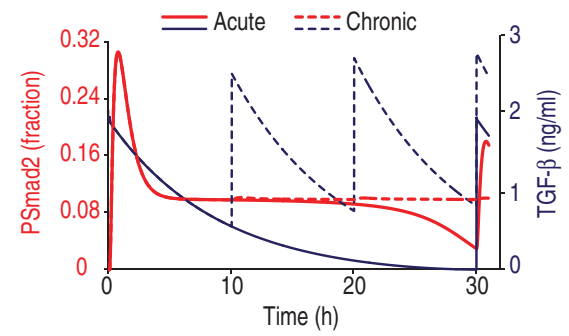

$\mathbf{F}$

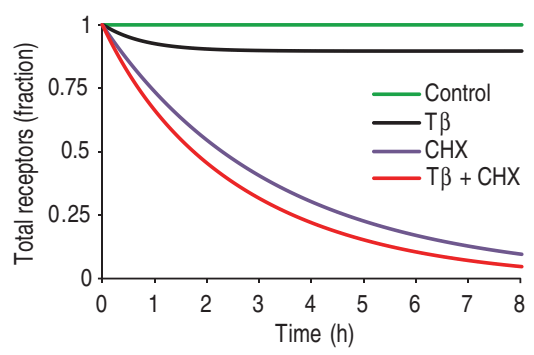

H

(Fig. 3D)

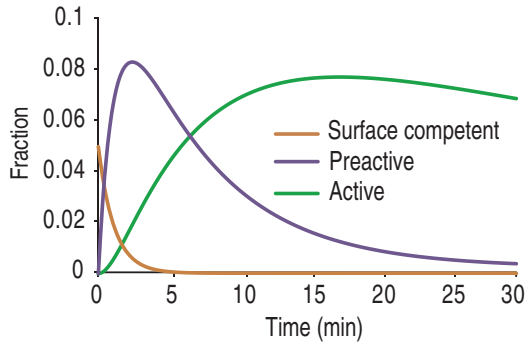

Fig. 5. Simulations of the refractory behavior and model fitting. (A) Simulation of the experiment shown in Fig. 2A (see also fig. S8D). PSmad2 (solid lines) and surface receptor (dashed lines) in cells treated with TGF- $\beta$ plus neutralizing antibody after 1, 5, or 10 min are shown. (B) Simulation of the TGF- $\beta$ dose experiment shown in Fig. 2B. (C) Simulation of the experiment shown in Fig. $2 \mathrm{C}$ (see also fig. S8E). After a 4-hour stimulation with TGF- $\beta$ followed by a 4-hour incubation with neutralizing antibody, cells were washed and allowed to recover for 4, 8, 12, and 24 hours, before restimulation with TGF- $\beta$ for 1 hour. PSmad 2 and signaling-competent surface receptors are shown. (D) Simulation of acute versus chronic TGF- $\beta$ (experiment in Fig. 2D; see also fig. S8F). Cells were treated with TGF- $\beta$ once (acute) or every 10 hours (chronic) for 30 hours. Solid lines depict PSmad2 and TGF- $\beta$ levels for acute treatment, and dashed lines for chronic treatment. (E) Time course simulation in cells treated with TGF- $\beta \pm$ cycloheximide $(\mathrm{CHX}) \pm$ MG-132 (MG) or MG-132 followed by SB-431542 (SBI) (see Fig. 3, A and B, and fig. S9). MG-132 was assumed to inhibit degradation by $80 \%$. (F) Total receptors in cells treated as indicated (see Fig. 3C and fig. S9). (G) Simulation of the surface receptor biotinylation experiment shown in Fig. 3D and ligand depletion. $(\mathrm{H})$ Receptor behavior during the first 30 min of the model simulation shown in Fig. 4B. The relevant experimental data are shown in Fig. 3D. 
A

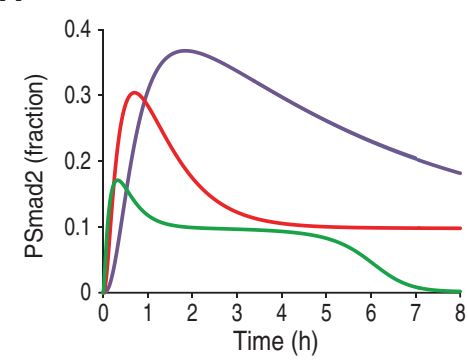

B

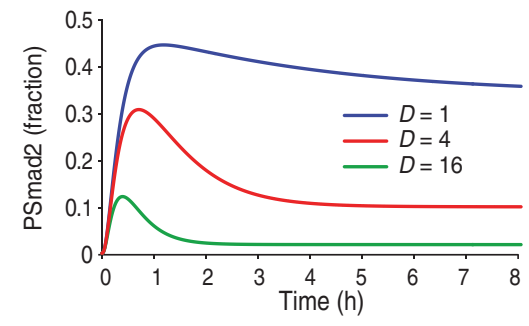

C

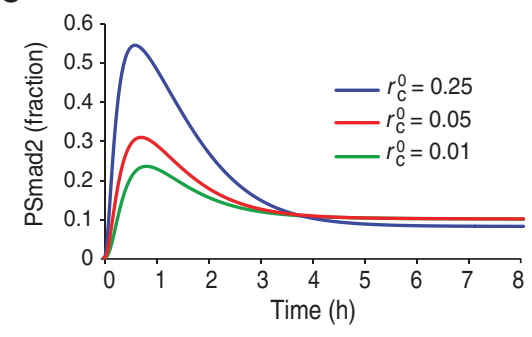

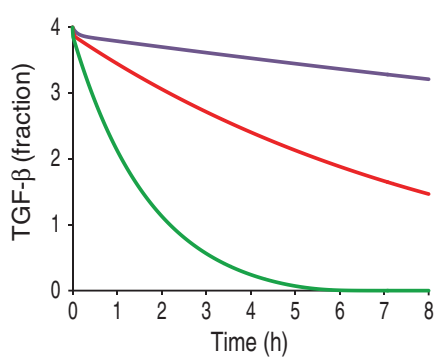
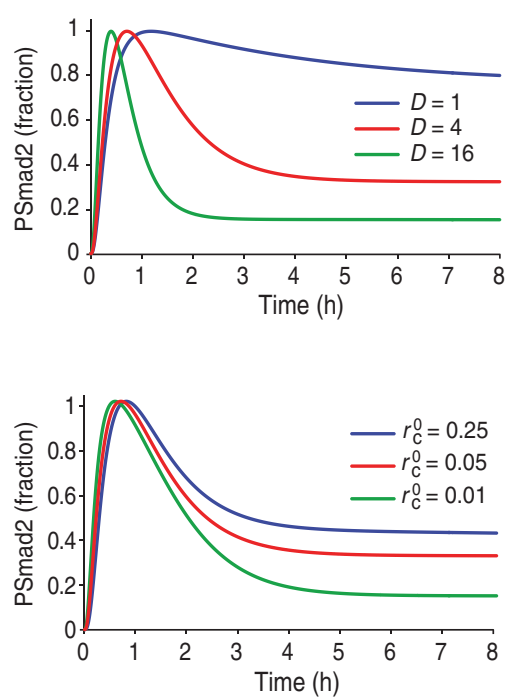

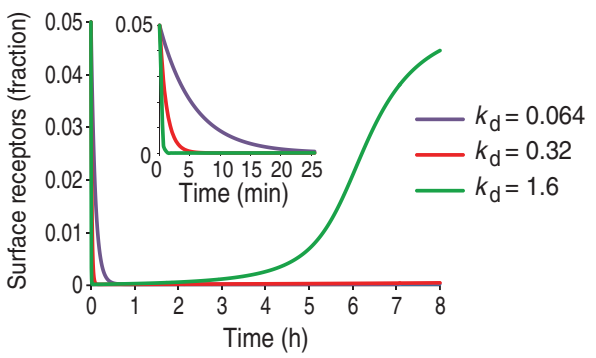

Fig. 6. Defining the determinants of signaling kinetics. (A) Receptor turnover is a major determinant of the signaling kinetics. Receptor halflife was set to $\sim 10$ hours $\left(k_{d}=0.064\right.$, blue), the measured value of $\sim 2$ hours $\left(k_{d}=0.32\right.$, red), or to $\sim 0.4$ hour $\left(k_{d}=1.6\right.$, green). This parameter influences the kinetics of Smad2 activation (left panel), TGF- $\beta$ depletion (middle panel), length of the refractory period (right panel), and rate of the depletion of surface receptors (right panel, inset). (B and $\mathrm{C}$ ) Varying parameter $D$ strongly affects the signaling kinetics (B), but varying the initial amount of surface receptors does not $(\mathrm{C})$. In (B) and (C), the left panels show the actual simulation results. The right panels show the results normalized such that the peak value achieved was 1 to facilitate the comparison of the kinetics. All parameters except for the one indicated were kept constant. receptors (Fig. 6C) does not significantly affect the kinetic behavior. The steps identified here as strong effectors of signaling behavior are likely to be subject to regulation.

\section{The mathematical model as a tool to simulate complex physiological conditions}

In vivo, particularly in pathological contexts such as late-stage tumors, cells exhibit autocrine TGF- $\beta$ signaling (17). Therefore, we expanded the model to include a TGF- $\beta$ production term, which describes TGF- $\beta$ synthesis as a function of transcriptionally active nuclear Smad complexes (text S3, "Modeling autocrine signaling"). Different rates of ligand synthesis were applied, and the amount of PSmad2, TGF- $\beta$, and surface receptors was predicted using the model. The simulations indicate that cell behavior shows an ultrasensitive response to changes in the TGF- $\beta$ production rate, which defines two qualitatively distinct types of behavior. To quantify the steepness of the threshold and thus the degree of ultrasensitivity (25), we fitted a Hill function to the simulation, obtaining a Hill coefficient of 9 , indicating an ultrasensitive response (Fig. 7A). If the TGF- $\beta$ production rate is below the threshold, cells consume essentially all they produce, the TGF- $\beta$ concentration in the medium stays close to zero, and no autocrine signaling is observed. If TGF- $\beta$ production is above the threshold, cells produce more TGF- $\beta$ than they consume, TGF- $\beta$ accumulates, and cells exhibit autocrine signaling, with amounts of PSmad2 similar to the attenuated level reached during chronic signaling observed in cultured cells. Close to the threshold, the transition between these two states is triggered by a small increase in the TGF- $\beta$ production rate (Fig. 7A).
Cells in these distinct states are expected to respond very differently to an acute stimulus. A cell with low autocrine activity will respond to an acute stimulation by TGF- $\beta$ and return to the original basal nonsignaling state after some time, depending on the rate of ligand depletion (Fig. 7B). By contrast, cells with high autocrine activity are predicted to show only a weak response when stimulated acutely because they are in a refractory state (Fig. 7C).

To test these predictions, we used a well-characterized series of cell lines derived from different stages of mouse skin carcinogenesis (26). The CN5 cell line is a mouse keratinocyte line, the PDV cell line was derived from a squamous carcinoma, and the H11 and D3 cell lines were derived from late-stage, spindle cell tumors. We first investigated the ability of these cell lines to produce active TGF- $\beta$ by applying conditioned medium from cultures of these cells to naïve $\mathrm{HaCaT}$ cells and measuring PSmad2. Only the spindle cell tumor cell line D3 produced sufficient TGF- $\beta$ to induce phosphorylation of Smad 2 in these conditions (Fig. 7D, left panels). In agreement with the model prediction, the ability of the D3 cell line to stimulate phosphorylation of Smad 2 in response to exogenous TGF- $\beta$ was substantially less than that of the other three related cell lines, which did not produce sufficient TGF- $\beta$ to activate naïve cells (Fig. 7D, right panels). Similar results were obtained if the conditioned medium from D3 cells was used instead of TGF- $\beta$ (fig. S10). Consistent with the lower TGF- $\beta$ inducibility of the cell lines derived from spindle cell tumors, they exhibited lower levels of surface type I receptor compared with the CN5 and PDV cells (Fig. 7E). 
A

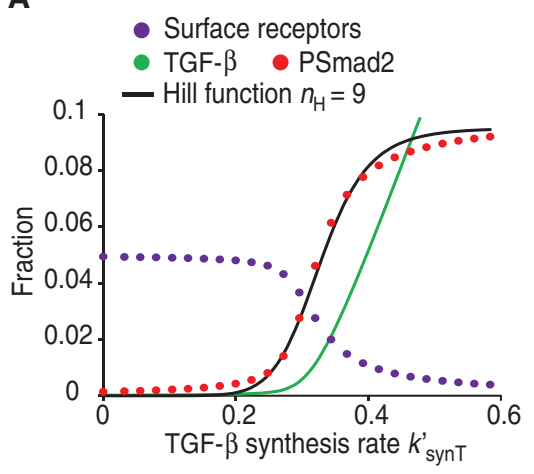

B

Slow TGF- $\beta$ synthesis -

no autocrine signalling

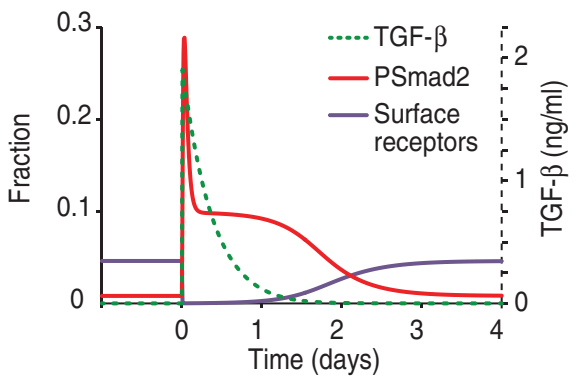

C

Fast TGF- $\beta$ synthesis autocrine signalling

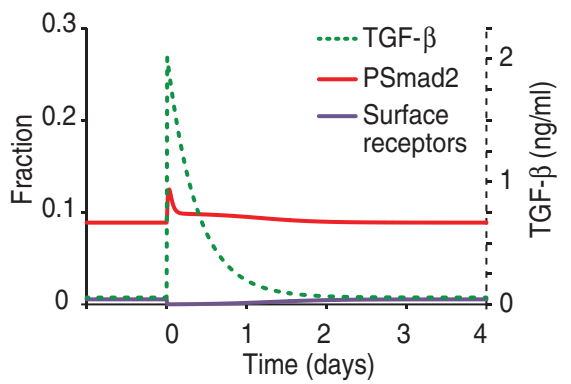

E

D

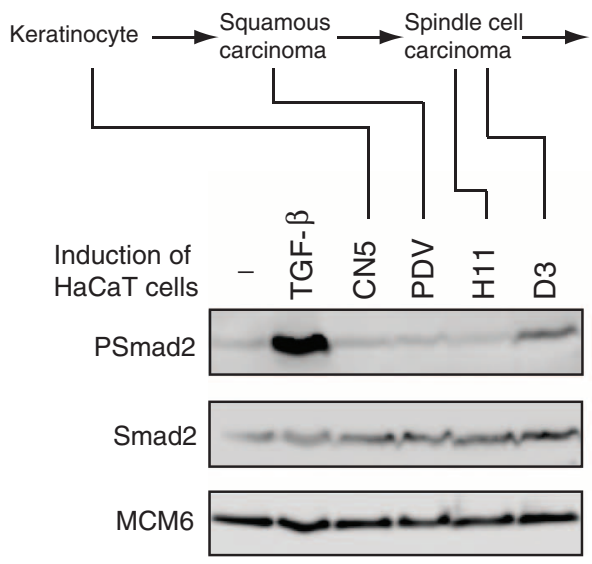
Metastasis

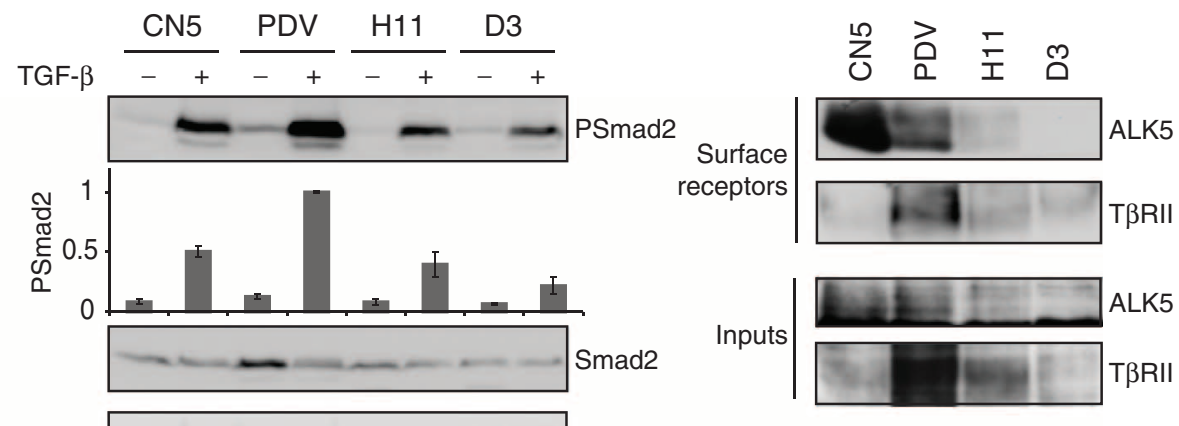

Fig. 7. Mathematical model predictions of TGF- $\beta$ signaling in complex systems. (A) Autocrine signaling and its effects on the response. TGF- $\beta$ synthesis as a function of the amount of Smad2-Smad4 complexes in the nucleus was included in the model to simulate signal-dependent autocrine signaling. Steady-state amounts of the indicated species are plotted with respect to the rate constant of TGF- $\beta$ synthesis. The ultrasensitive response as a function of the TGF- $\beta$ synthesis rate defines two qualitatively distinct regimes. (B) Acute TGF- $\beta$ stimulation of a cell with low TGF- $\beta$ synthesis rate $\left(K_{\text {synT }}^{\prime}=0.25\right)$. The cell responds strongly to the signal. (C) Acute TGF- $\beta$ stimulation of a cell with high TGF- $\beta$ synthesis rate $\left(k_{\text {synt }}^{\prime}=0.5\right)$. Even before the acute stimulation, surface receptors are low, and the cell is in a refrac-

\section{DISCUSSION}

Here, we have assessed the response of cells to acute, chronic, and repeated TGF- $\beta$ stimulation. We found that an acute stimulus renders cells refractory to further acute TGF- $\beta$ stimulation. The data from cultured cells indicated that cells enter such a refractory state because surface receptors were rapidly occupied and internalized, whereas replenishment of the receptors at the cell surface was very slow. The refractory state was induced by TGF- $\beta$ binding to receptors and did not require negative feedback through TGF- $\beta$ target genes. As long as excess ligand was still present in the extracellular environment, the very low steady-state amounts of surface TGF- $\beta$ receptors present after an acute response dictated the magnitude of steady-state signaling. Cell-dependent depletion of TGF- $\beta$ from the medium (15) was not required for signal attenuation, but was essential for the ability of the cells to regain response competence after the refractory period. Once the ligand was depleted or consumed, cell surface re- tory state and does not react proportionally to acute stimulation. (D) Left panels: TGF- $\beta$ or medium from CN5, PDV, H11, or D3 cells, which represent sequential stages of mouse skin carcinogenesis, was added to naïve HaCaT cells, and PSmad2 abundance was detected by Western blot after 1 hour. Right panels: CN5, PDV, H11, and D3 cell lines were stimulated for 1 hour with TGF- $\beta$, and induction of PSmad2 was measured. Quantifications are normalized (relative to the most highly induced cell line, PDV) and presented as the average and ranges of two independent experiments. (E) Amounts of surface receptors were measured using surface biotinylation assay. Whole-cell lysates were also assayed by Western blotting for ALK5 and T $\beta R I I$. A representative blot of three independent experiments is shown for each panel.

ceptor levels were slowly restored and the cells became once more fully competent to respond to an acute stimulation. For the purposes of this study, we used phosphorylation of Smad 2 as a readout of receptor activity, although Smad-independent signaling has been reported (27), and it will be interesting in the future to extend the model to incorporate this. The behavior we report here for the TGF- $\beta$ signaling pathway is in contrast to some other signaling pathways, for instance, that downstream of the erythropoietin receptor (EpoR). In this case, the amount of unoccupied cell surface EpoR recovers very quickly after ligand stimulation and the system never reaches a refractory state (28). Moreover, cells regain their ability to respond fully to an acute stimulation just 2 hours after an initial Epo signal, compared with $\sim 48$ hours for TGF- $\beta$ signaling.

Our experiments demonstrated a marked difference in the kinetic behavior of T $\beta$ RII and that of ALK5. T $\beta$ RII was substantially depleted from the plasma membrane within 10 min of TGF- $\beta$ treatment, whereas ALK5 
was only maximally depleted after 4 hours. A possible explanation for the initially stable surface amount of ALK5 is that ALK5 might be in excess over T $\beta$ RII. Eventually, ALK5 was also depleted, probably as a result of TGF- $\beta$ stimulating the interaction of ALK5 with newly synthesized T $\beta$ RII, which is constantly trafficked to the cell surface (23). The data thus indicated that it is the loss of surface-exposed T $\beta$ RII rather than the loss of surface-exposed ALK5 that determines the kinetics of signal attenuation. At present, we cannot exclude that synthesis and trafficking of ALK5 are rate-limiting in the slow restoration of surface receptors after depletion of ligand.

Having deduced a working hypothesis, we built a mathematical model to determine whether it was possible to construct a signaling network with which we could computationally simulate the observed behaviors associated with long-term TGF- $\beta$ signaling. The resulting model consistently explained all our data, both qualitatively and semiquantitatively, and enabled us to make predictions, and the successful verification of these predictions provided additional support for the proposed mechanism.

We used the mathematical model to predict which parameters were critical determinants of the dynamics of TGF- $\beta$ signaling. The kinetic properties of attenuation and the refractory state are determined by the rate of receptor turnover and the ratio of ligand-induced to constitutive receptor degradation (factor $D$ ), but not by the initial amount of surface receptors. Thus, enzymes involved in regulating receptor turnover, such as E3 ubiquitin ligases, deubiquitinating enzymes, lysosomal enzymes, or regulators thereof, are likely to be crucial determinants of the kinetics of TGF- $\beta$ pathway signaling and also the rate of ligand consumption.

These results are crucial for understanding the response of cells in vivo to both chronic and acute TGF- $\beta$ signals. TGF- $\beta$ is normally produced in a latent form in which the prodomain remains tightly associated with the mature ligand, even after cleavage. Further local activation is then required to produce active TGF- $\beta$ (29). We propose that this ligand activation mechanism may be important in vivo to limit the exposure of cells to high concentrations of mature TGF- $\beta$ that would provoke a refractory state. Indeed, high TGF- $\beta$ exposure is associated with disease states, for example, during wound healing, fibrosis, or in tumorigenesis $(2,30)$. The consequence of exposure to high concentrations of TGF- $\beta$ is not only acute pathway activation but also desensitization. Therefore, a tumor that receives a constant supply of TGF- $\beta$, either because of autocrine signaling as exemplified by the D3 cell line or through production of TGF- $\beta$ by stromal cells (30), would maintain only a low level of signaling. This would allow expression of a subset of TGF- $\beta$ genes, but keep silent those that require a strong acute signal. Chronic exposure of tumors to TGF- $\beta$ could explain the loss of specific TGF- $\beta$ responses in tumors in vivo (30). This conclusion is based on the assumption that receptor trafficking in tumor cells is as we have observed in HaCaTs. Tumors that contain additional mutations such that receptor trafficking or degradation is perturbed may be resistant to ligand-induced desensitization.

The requirement for ligand consumption or "neutralization" for resensitization of cells to further ligand stimulation may explain the plethora of natural ligand antagonists known for the TGF- $\beta$ superfamily. This is particularly true of the ligands of the BMP (bone morphogenetic protein), Nodal, and Activin families, for which the antagonists are important in early embryogenesis $(31,32)$. Assuming that these ligands signal in an analogous way to that described here for TGF- $\beta$, it is tempting to speculate that the production of ligand antagonists in response to ligand stimulation, such as the production of Lefty in response to Nodal signaling in vertebrate embryos (33), might act to prevent ligand binding to receptors. This would allow competent surface receptors to reaccumulate, thus sensitizing cells for further Nodal stimulation. The time course of recovery from the refractory period described here for TGF- $\beta$ is 12 to 24 hours, which is of the order of one cell cycle. In early vertebrate development, where cell cycles are much shorter and signaling is very dynamic, recovery is expected to be faster. To understand how these ligands function in early embryos, it will be important to extend this model in the future to other TGF- $\beta$ superfamily members.

\section{MATERIALS AND METHODS}

\section{Cell lines, treatments, and immunoblotting}

The human keratinocyte cell line, HaCaT, was used throughout the study, except where indicated. All cells were maintained in Dulbecco's modified Eagle's medium (DMEM) $/ 10 \%$ fetal calf serum. Conditioned medium from the CN5, PDV, H11, and D3 cell lines was concentrated fourfold before using it to stimulate naïve $\mathrm{HaCaT}$ or cancer cells. Ligands and reagents were used at the following concentrations: TGF- $\beta$ (PeproTech), $2 \mathrm{ng} / \mathrm{ml}$, except where stated otherwise; cycloheximide (Sigma), $20 \mu \mathrm{g} / \mathrm{ml}$; MG-132 (Tocris), $50 \mu \mathrm{M}$; SB-431542 (Tocris), $10 \mu \mathrm{M}$. The TGF- $\beta$ neutralizing antibody (1D11) recognizing all three TGF- $\beta$ isoforms and the isotype-matched IgG1 monoclonal antibody raised against Shigella toxin (13C4) were as described (20) and used at $30 \mu \mathrm{g} / \mathrm{ml}$. To remove SB-431542, the neutralizing antibody, or both, cells were washed three times with warm medium. Except for the biotinylation experiments, whole-cell extracts were prepared as described (34). Immunoblotting was performed with the following antibodies: anti-phospho-Smad2 (Millipore, catalog \# 04-953), anti-Smad2/3 (BD Biosciences, catalog \# 610843), anti-Grb2 (BD Biosciences, catalog \# 610112), anti-ALK5 (Santa Cruz Biotechnology, V-22), anti-TßRII (Santa Cruz Biotechnology, E6), anti-MCM7 (Santa Cruz Biotechnology, 141.2), anti-MCM6 (Santa Cruz Biotechnology, C-20), and anti-tubulin (Abcam, catalog \# Ab6160). Western blots were visualized with an ImageQuant LAS 4000 mini (GE Healthcare) and quantified with ImageQuant TL software version 7.0 (GE Healthcare) or ImageJ.

\section{Surface biotinylation experiments}

Cells were treated, or not, with TGF- $\beta$ for the times indicated, then were immediately placed on ice, washed twice with ice-cold phosphate-buffered saline (PBS)/CM (PBS containing $0.8 \mathrm{mM} \mathrm{MgCl}_{2}$ and $1 \mathrm{mM} \mathrm{CaCl}_{2}$ ), and labeled for $40 \mathrm{~min}$ with Sulfo-NHS-SS-biotin $(6 \mathrm{mg} / \mathrm{ml})$ (Pierce) in PBS/ $\mathrm{CM}$. Biotinylation was then quenched with $20 \mathrm{mM}$ tris- $\mathrm{HCl}$ (pH 7.4). The reduced control was subsequently treated with reducing solution $(50 \mathrm{mM}$ glutathione $/ 75 \mathrm{mM} \mathrm{NaCl}$, neutralized with $75 \mathrm{mM} \mathrm{NaOH}$ ) for $40 \mathrm{~min}$ at $4^{\circ} \mathrm{C}$ to remove the biotin, followed by iodoacetamide $(2.5 \mathrm{mg} / \mathrm{ml})$ dissolved in $\mathrm{PBS} / \mathrm{CM} / 1 \%$ bovine serum albumin to quench the free $\mathrm{SH}$ groups. All cells were then lysed in lysis buffer (PBS containing 1\% Triton $\mathrm{X}-100,0.1 \%$ SDS, $10 \mathrm{mM}$ EDTA, and protease inhibitors) and subjected to streptavidin pull-down with NeutrAvidin beads (Pierce) overnight at $4{ }^{\circ} \mathrm{C}$. Eluted samples were analyzed by Western blotting as described above.

\section{TGF- $\beta 1$ ELISA}

The amount of TGF- $\beta$ was monitored in the medium after ligand stimulation with the human TGF- $\beta 1$ Quantikine ELISA assay kit (R\&D Systems) according to the manufacturer's instructions.

\section{Model implementation}

Details of the model construction are given in the Supplementary Materials. The model was implemented in the freely available software packages COPASI (http://www.copasi.org) and XPP (http://www.math.pitt. edu/ bard/xpp/xpp.html). All simulations and parameter fitting were performed in COPASI (35). The model for the Smad module was as in the 
original publication (4), but was converted from seconds into hours and expressed in dimensionless form.

\section{SUPPLEMENTARY MATERIALS}

www.sciencesignaling.org/cgi/content/full/6/305/ra106/DC1 Texts $\mathrm{S} 1$ to $\mathrm{S} 3$

Fig. S1. The refractory period is not unique to HaCaT cells.

Fig. S2. Kinetics of Smad2 phosphorylation.

Fig. S3. Blocking and depletion of ligand.

Fig. S4. Specificity of the T $\beta R I I$ antibody in Western blotting.

Fig. S5. Recovery from the refractory state.

Fig. S6. Biotinylation of surface receptors in $\mathrm{HaCaT}$ cells at different time points.

Fig. S7. Data fitting with previous data sets.

Fig. S8. Comparison between simulations and experimental data in Figs. 1 and 2 .

Fig. S9. Comparison between simulations and experimental data in Fig. 3.

Fig. S10. Restimulation of naïve cancer cell lines with medium from the D3 line.

Table S1. Model parameters.

Table S2. List of model species.

Table S3. Ordinary differential equations and initial conditions.

References $(36,37)$

\section{REFERENCES AND NOTES}

1. X. H. Feng, R. Derynck, Specificity and versatility in TGF- $\beta$ signaling through Smads Annu. Rev. Cell Dev. Biol. 21, 659-693 (2005).

2. G. C. Blobe, W. P. Schiemann, H. F. Lodish, Role of transforming growth factor $\beta$ in human disease. N. Engl. J. Med. 342, 1350-1358 (2000).

3. A. Moustakas, C. H. Heldin, The regulation of TGF $\beta$ signal transduction. Development 136, 3699-3714 (2009)

4. B. Schmierer, A. L. Tournier, P. A. Bates, C. S. Hill, Mathematical modeling identifies Smad nucleocytoplasmic shuttling as a dynamic signal-interpreting system. Proc. Natl. Acad. Sci. U.S.A. 105, 6608-6613 (2008).

5. Y. G. Chen, Endocytic regulation of TGF- $\beta$ signaling. Cell Res. 19, 58-70 (2009).

6. G. M. Di Guglielmo, C. Le Roy, A. F. Goodfellow, J. L. Wrana, Distinct endocytic pathways regulate TGF- $\beta$ receptor signalling and turnover. Nat. Cell Biol. 5, 410-421 (2003).

7. M. Ehrlich, A. Shmuely, Y. I. Henis, A single internalization signal from the di-leucine family is critical for constitutive endocytosis of the type II TGF- $\beta$ receptor. J. Cell Sci. 114, 1777-1786 (2001)

8. B. Schmierer, C. S. Hill, TGF $\beta$-SMAD signal transduction: Molecular specificity and functional flexibility. Nat. Rev. Mol. Cell Biol. 8, 970-982 (2007).

9. G. J. Inman, F. J. Nicolás, C. S. Hill, Nucleocytoplasmic shuttling of Smads 2, 3, and 4 permits sensing of TGF- $\beta$ receptor activity. Mol. Cell 10, 283-294 (2002).

10. S. Itoh, P. ten Dijke, Negative regulation of TGF- $\beta$ receptor/Smad signal transduction. Curr. Opin. Cell Biol. 19, 176-184 (2007).

11. T. Ebisawa, M. Fukuchi, G. Murakami, T. Chiba, K. Tanaka, T. Imamura, K. Miyazono, Smurf1 interacts with transforming growth factor- $\beta$ type I receptor through Smad7 and induces receptor degradation. J. Biol. Chem. 276, 12477-12480 (2001).

12. P. Kavsak, R. K. Rasmussen, C. G. Causing, S. Bonni, H. Zhu, G. H. Thomsen, J. L. Wrana, Smad7 binds to Smurf2 to form an E3 ubiquitin ligase that targets the TGF $\beta$ receptor for degradation. Mol. Cell 6, 1365-1375 (2000).

13. W. Shi, C. Sun, B. He, W. Xiong, X. Shi, D. Yao, X. Cao, GADD34-PP1c recruited by Smad7 dephosphorylates TGF $\beta$ type I receptor. J. Cell Biol. 164, 291-300 (2004).

14. C. Alarcón, A. I. Zaromytidou, Q. Xi, S. Gao, J. Yu, S. Fujisawa, A. Barlas, A. N. Miller, K. Manova-Todorova, M. J. Macias, G. Sapkota, D. Pan, J. Massagué, Nuclear CDKs drive Smad transcriptional activation and turnover in BMP and TGF- $\beta$ pathways. Cell 139, 757-769 (2009).

15. D. C. Clarke, M. L. Brown, R. A. Erickson, Y. Shi, X. Liu, Transforming growth factor $\beta$ depletion is the primary determinant of Smad signaling kinetics. Mol. Cell. Biol. 29, 2443-2455 (2009)

16. C. E. Pierreux, F. J. Nicolás, C. S. Hill, Transforming growth factor $\beta$-independent shuttling of Smad4 between the cytoplasm and nucleus. Mol. Cell. Biol. 20, 9041-9054 (2000).

17. S. J. Kim, P. Angel, R. Lafyatis, K. Hattori, K. Y. Kim, M. B. Sporn, M. Karin, A. B. Roberts, Autoinduction of transforming growth factor $\beta 1$ is mediated by the AP-1 complex. Mol. Cell. Biol. 10, 1492-1497 (1990)

18. H. Mitchell, A. Choudhury, R. E. Pagano, E. B. Leof, Ligand-dependent and -independent transforming growth factor- $\beta$ receptor recycling regulated by clathrin-mediated endocytosis and Rab11. Mol. Biol. Cell 15, 4166-4178 (2004).

19. C. Le Roy, J. L. Wrana, Clathrin- and non-clathrin-mediated endocytic regulation of cell signalling. Nat. Rev. Mol. Cell Biol. 6, 112-126 (2005).
20. J. S. Nam, M. Terabe, M. Mamura, M. J. Kang, H. Chae, C. Stuelten, E. Kohn, B. Tang, H. Sabzevari, M. R. Anver, S. Lawrence, D. Danielpour, S. Lonning, J. A. Berzofsky, L. M. Wakefield, An anti-transforming growth factor $\beta$ antibody suppresses metastasis via cooperative effects on multiple cell compartments. Cancer Res. 68, 3835-3843 (2008).

21. E. Grönroos, I. J. Kingston, A. Ramachandran, R. A. Randall, P. Vizán, C. S. Hill, Transforming growth factor $\beta$ inhibits bone morphogenetic protein-induced transcription through novel phosphorylated Smad1/5-Smad3 complexes. Mol. Cell. Biol. 32, 2904-2916 (2012)

22. K. M. Koli, C. L. Arteaga, Processing of the transforming growth factor $\beta$ type I and II receptors. Biosynthesis and ligand-induced regulation. J. Biol. Chem. 272, 6423-6427 (1997).

23. R. G. Wells, H. Yankelev, H. Y. Lin, H. F. Lodish, Biosynthesis of the type I and type II TGF- $\beta$ receptors. Implications for complex formation. J. Biol. Chem. 272, 11444-11451 (1997).

24. J. M. Vilar, R. Jansen, C. Sander, Signal processing in the TGF- $\beta$ superfamily ligandreceptor network. PLOS Comput. Biol. 2, e3 (2006).

25. Q. Zhang, S. Bhattacharya, M. E. Andersen, Ultrasensitive response motifs: Basic amplifiers in molecular signalling networks. Open Biol. 3, 130031 (2013).

26. M. Oft, R. J. Akhurst, A. Balmain, Metastasis is driven by sequential elevation of $\mathrm{H}$-ras and Smad2 levels. Nat. Cell Biol. 4, 487-494 (2002).

27. Y. Mu, S. K. Gudey, M. Landström, Non-Smad signaling pathways. Cell Tissue Res. 347, 11-20 (2012)

28. V. Becker, M. Schilling, J. Bachmann, U. Baumann, A. Raue, T. Maiwald, J. Timmer, U. Klingmüller, Covering a broad dynamic range: Information processing at the erythropoietin receptor. Science 328, 1404-1408 (2010).

29. J. P. Annes, J. S. Munger, D. B. Rifkin, Making sense of latent TGF $\beta$ activation. J. Cell Sci. 116, 217-224 (2003)

30. J. Massagué, TGF $\beta$ in cancer. Cell 134, 215-230 (2008).

31. E. M. De Robertis, H. Kuroda, Dorsal-ventral patterning and neural induction in Xenopus embryos. Annu. Rev. Cell Dev. Biol. 20, 285-308 (2004).

32. M. Y. Wu, C. S. Hill, TGF- $\beta$ superfamily signaling in embryonic development and homeostasis. Dev. Cell 16, 329-343 (2009).

33. A. F. Schier, Nodal signaling in vertebrate development. Annu. Rev. Cell Dev. Biol. 19, 589-621 (2003)

34. G. J. Inman, F. J. Nicolás, J. F. Callahan, J. D. Harling, L. M. Gaster, A. D. Reith, N. J. Laping, C. S. Hill, SB-431542 is a potent and specific inhibitor of transforming growth factor- $\beta$ superfamily type I activin receptor-like kinase (ALK) receptors ALK4, ALK5, and ALK7. Mol. Pharmacol. 62, 65-74 (2002).

35. S. Hoops, S. Sahle, R. Gauges, C. Lee, J. Pahle, N. Simus, M. Singhal, L. Xu, P. Mendes, U. Kummer, COPASI-A COmplex PAthway SImulator. Bioinformatics 22, 3067-3074 (2006)

36. Z. Zi, Z. Feng, D. A. Chapnick, M. Dahl, D. Deng, E. Klipp, A. Moustakas, X. Liu, Quantitative analysis of transient and sustained transforming growth factor- $\beta$ signaling dynamics. Mol. Syst. Biol. 7, 492 (2011)

37. E. Kalkhoven, B. A. Roelen, J. P. de Winter, C. L. Mummery, A. J. van den Eijnden-van Raaij, P. T. van der Saag, B. van der Burg, Resistance to transforming growth factor $\beta$ and activin due to reduced receptor expression in human breast tumor cell lines. Cell Growth Differ. 6, 1151-1161 (1995).

Acknowledgments: We thank L. Wakefield for providing the neutralizing antibody and the isotype-matched control, and R. Akhurst for the mouse keratinocytes and skin tumor cell lines. We thank B. Novák and Y.-G. Chen for helpful advice, and the Hill Lab, U. Klingmüller, B. Stell, E. Sahai, and N. Tapon for stimulating discussions and comments on the manuscript. Funding: This work was funded by the Cancer Research UK, the European Commission Network of Excellence EpiGeneSys (HEALTH-F4-2010-257082), core funding from the Biotechnology and Biological Sciences Research Council (B.S.), and a Marie Curie Intra-European Fellowship (PIEF-GA-2009-235995, to P.V.). Author contributions: P.V., B.S., and C.S.H. designed the research; P.V., B.S., D.S.J.M., I.G., and D.D. performed the research; P.V., B.S., D.S.J.M., and I.G. analyzed the data; and P.V., B.S., D.S.J.M., and C.S.H. wrote the paper. Competing interests: The authors declare that they have no competing interests. Data and materials availability: The model is available from the BioModels Database (http://www.ebi.ac.uk/biomodels), accession number MODEL1203120000.

Submitted 13 June 2013

Accepted 19 November 2013

Final Publication 10 December 2013

10.1126/scisignal.2004416

Citation: P. Vizán, D. S. J. Miller, I. Gori, D. Das, B. Schmierer, C. S. Hill, Controlling longterm signaling: Receptor dynamics determine attenuation and refractory behavior of the TGF- $\beta$ pathway. Sci. Signal. 6, ra106 (2013). 